\title{
COMBINATION OF IMMUNOCYTOCHEMISTRY AND RADIOLIGAND RECEPTOR ASSAY TO IDENTIFY $\beta$-ADRENERGIC RECEPTOR SUBTYPES ON ASTROGLIA IN VITRO ${ }^{1}$
}

\author{
PATRICIA A. TRIMMER, ${ }^{2}$ TONY EVANS, MCHARDY M. SMITH, T. KENDALL HARDEN, ${ }^{3}$ AND \\ KEN D. MCCARTHY
}

Department of Pharmacology, University of North Carolina School of Medicine, Chapel Hill, North Carolina 27514

Received July 27, 1983; Revised January 4, 1984; Accepted January 24, 1984

\begin{abstract}
There is an increasing need to assess the distribution of receptors for neuroactive substances on specific neural cell types. This study describes the establishment of methodology that combines the quantification of $\beta$-adrenergic receptor subtypes by radioligand binding assays with immunocytochemical analysis of the contribution of astroglia (identified by the presence of glial fibrillary acidic protein) and fibroblasts (identified by the presence of fibronectin) to cultures prepared from neonatal rat cercbral cortex. The effects of subtle changes in culture methodology on the cellular composition of cerebral cortical cultures and the distribution of $\beta$-adrenergic receptor subtypes were examined. The data indicate that (1) a decrease in the density of the initial plating suspension, (2) an increase in the age of the animals, or (3) supplementation of the cortical cell suspension with meningeal fibroblasts all result in an increase in fibronectin staining and a decrease in glial fibrillary acidic protein antibody staining. This change in the cellular composition of the cortical cultures correlated with an increase in the number of $\beta_{2}$-adrenergic receptors and a corresponding decrease in the number of $\beta_{1}$-adrenergic receptors. These observations point out the carc which must be exercised when preparing primary astroglial cultures of sufficient purity for large-scale biochemical and pharmacological studies.
\end{abstract}

The complexity and heterogeneity of the mammalian central nervous system have significantly retarded attempts to define and localize the biochemical mechanisms that regulate cellular function and cell-cell interaction. The problems created by this heterogeneity have led to the use of tissue culture model systems. In many situations, clonal cell lines have been utilized to circumvent this problem. For example, using cell lines it was possible to establish that glial cells as well as neurons express $\beta$-adrenergic receptors (Clark and Perkins, 1971; Pfeiffer el al., 1977). In situations where the activity under investigation is restricted to one cell class (i.e., either neurons, astrocytes, or oligodendrocytes), it has been possible to use primary cultures of neural cells to assign the biochemical function to a specific cell type.

\footnotetext{
${ }^{1}$ This work was supported by United States Public Health Service Grant NS 16992. A preliminary report of portions of this work has been presented (Evans et al,, 1983). We are indebted to Angie Hodgin for her help in preparing this manuscript.

${ }^{2}$ To whom correspondence should be addressed.

${ }^{3}$ Established Investigator of the American Heart Association.
}

For instance, work from this laboratory (McCarthy and Harden, 1981) established that the clinically relevant benzodiazepine receptor is expressed by cultured neurons but not by astroglia or oligodendroglia. It is apparent that as investigators attempt to establish the cellular distribution of discrete biochemical activities (i.e., isoenzymes, receptor subtypes, or metabolic processes) rigorously defined primary culture systems will become in creasingly valuable.

The methodologies currently used to prepare astroglial cultures vary substantially. There has been little investigation of the influence of this variation in culture methodology on the composition of these cultures. With this concern in mind, we have developed a means of correlating the presence of a biochemical activity (e.g., the expression of $\beta$-adrenergic receptor subtypes) with the cellular composition of CNS cultures. Previous studies of the changes in levels of $\beta$-adrenergic receptor subtypes in response to drug treatment in vivo (Minneman et al., 1979c) suggested that $\beta_{1}$-adrenergic receptors in the cerebral cortex are located at the postsynaptic sites of innervated cells, while $\beta_{2}$-adrenergic receptors are confined to vascular tissue or glial cells. Subsequent characterization of the $\beta$-adrenergic receptors expressed 
on cultured astroglia from neonatal mouse brain (Ebersolt et al., 1981a, b) by radioligand binding assay and adenylate cyclase activation studies suggested that astroglial cells exhibit both $\beta_{1}$ - and $\beta_{2}$-adrenergic receptors in a ratio of approximately 60:40. In contrast, Harden and McCarthy (1982) demonstrated that membranes from purified cultures of astroglia prepared from the cerebral cortices of neonatal rats express mainly the $\beta_{1}$ adrenergic receptor. It was suggested that the discrepancy in receptor subtypes between these two studies could arise from differences in culture methodology that can alter the proportion of cell types. For example, fibroblasts derived from the meninges represent a very predictable source of contamination in primary CNS cell culture. These cells proliferate rapidly in vitro and, therefore, even when initially present in small numbers, can contribute significantly to the cellular composition of confluent culture preparations. Since the $\beta$-adrenergic receptor subtype expressed by meningeal fibroblasts is $\beta_{2}$ (Friedman and Davis, 1980; Ebersolt et al., 1981a, b; this study), these cells might be a source for receptors detected by Ebersolt et al. (1981a, b).

In the present study, radioligand binding assays were conducted on purified astroglial and mixed astroglialmeningeal cultures that had been double stained with antibody to both glial fibrillary acidic protein (GFAP), an astrocyte-specific antigen, and fibronectin, a large glycoprotein that is synthesized and secreted by meningeal fibroblasts in the CNS (Schachner et al. 1978; Stieg et al., 1980). The value of utilizing two cell-specific immunocytochemical markers was emphasized in the study of Stieg et al. (1980) which indicated that the purity of astroglial cultures can be overestimated by $20 \%$ or more when only GFAP staining is assessed. They reported that a more accurate appraisal of the culture composition could be obtained by immunocytochemical staining with both GFAP and fibronectin. Our analysis of astroglial cultures indicates that there is an increase in the amount of fibronectin and a comparable decrease in GFAP staining as a result of certain variations in culture technique. This change in the cellular composition of the cultures correlates with shifts in the relative proportion of $\beta_{1^{-}}$and $\beta_{2}$-adrenergic receptor subtypes. The results emphasize the value of using immunocytochemistry in combination with radioligand receptor assays to approach the specific cell localization of receptors in primary cultures of mammalian brain.

\section{Materials and Methods}

(-)-Pindolol and (-)-cyanopindolol were generously provided by Dr. Gunther Engel of Sandoz Pharmaceuticals (Basel, Switzerland). ICI 118,551 was a gift from Imperial Chemical Industries (Macclessfield, England), and metoprolol was provided by Dr. P. B. Molinoff.

Cell culture. The standard astroglial cell culture utilized for these studies was prepared essentially as previously described (McCarthy and de Vellis, 1980). Newborn rat pups were decapitated, their brains were rapidly removed, and cerebral cortices were peeled off and placed in saline I ( $138 \mathrm{mM} \mathrm{NaCl}, 5.4 \mathrm{mM} \mathrm{KCl}, 1.1 \mathrm{mM} \mathrm{Na} 2 \mathrm{HPO}_{2}$, and $22 \mathrm{~mm}$ glucose). After the cortices of 40 pups were collected, the meninges were stripped away using fine forceps. In many cases, the meninges were collected separately in saline I and were used to prepare meningeal cell cultures. The collected tissue was gently aspirated through a $10-\mathrm{ml}$ pipette and was transferred to a $50-\mathrm{ml}$ plastic Erlenmeyer flask. Following incubation for 15 min in a rotary shaker $\left(80 \mathrm{rpm}, 37^{\circ} \mathrm{C}\right)$ to loosen tissue fragments, sufficient trypsin (Difco Laboratories, Detroit, MI, 1:250, neutralized to $\mathrm{pH} 7.0$ in saline I) was added to the tissue suspension to reach a final concentration of $0.1 \%$. The tissue was incubated for an additional 25 to $30 \mathrm{~min}$ in the rotary shaker $\left(80 \mathrm{rpm}, 37^{\circ} \mathrm{C}\right)$, after which time the trypsinization was terminated by adding an equal amount of complete culture medium consisting of Eagle's Basal Medium (BME) with Earle's balanced salts containing $10 \%$ fetal calf serum, $0.1 \%$ glutamine, $0.6 \%$ glucose, $50 \mathrm{IU} / \mathrm{ml}$ of penicillin, and 50 $\mu \mathrm{g} / \mathrm{ml}$ of streptomycin). The large tissue fragments were allowed to settle, and suspended cells were removed and filtered through Nitex 130 (Tetko). The tissue fragments were dispersed by pipetting three to four more times, and the suspended cells were collected, filtered through Nitex 130 , and combined with the previous filtrate. This cell suspension was centrifuged at $100 \times g$ for 10 to $15 \mathrm{~min}$ at room temperature. The cell pellet was resuspended in complete medium and filtered through Nitex 33 . The number of viable cells in the suspension was determined with a hemacytometer using trypan blue dye exclusion. If necessary the suspension was further diluted to achieve a final density of approximately $4 \times 10^{5} \mathrm{cells} / \mathrm{cm}^{2}$. The cell suspension was plated into $75-\mathrm{cm}^{2}$ tissue culture flasks and was incubated in a humidified $5 \% \quad \mathrm{CO}_{2}$-air atmosphere. After between 10 and 12 days in vitro or when the cultures had reached confluency, the culture flasks were secured to a rotary shaker and shaken for 15 to $18 \mathrm{hr}\left(260 \mathrm{rpm}, 37^{\circ} \mathrm{C}\right)$ to remove process bearing cells overlying the bed of flat astroglia. Membranes of cultured cells were prepared for receptor binding studies within 1 to 3 days after the purification procedure.

Meningeal cell cultures were prepared in a similar manner. The meninges from 40 to 80 newborn rat pups were collected in saline I. Following a 30-min incubation in $0.1 \%$ trypsin on the rotary shaker, the meninges were dispersed by pipetting. The cell suspension was centrifuged at $100 \times g$ for $5 \mathrm{~min}$ at room temperature. The pellet was resuspended, and the cells were aliquoted into $75-\mathrm{cm}^{2}$ tissue culture flasks.

Purified astroglial cell cultures from the cerebral cortices of 6-day-old rats were prepared essentially as described above except that 50 to 60 animals were required to produce an equivalent cell plating density. A dissecting microscope was utilized to facilitate removal of the meninges.

Mixing and dilution experiments. In one series of experiments, meningeal fibroblasts were deliberately added to cerebral cortical cells to examine the effect of their addition on the proportion of $\beta$-adrenergic receptor subtypes. To prepare these cultures, newborn rat cortical cell and meningeal cell suspensions were prepared as described above. The total number of viable cells in each suspension was determined with a hemacytometer using trypan blue dye exclusion. The cortical cell suspension was diluted if necessary to achieve an optimum cell 
density $\left(2\right.$ to $4 \times 10^{5}$ cells $/ \mathrm{cm}^{2}$ ). The percentage of fibroblasts added to various culture preparations ranged from 1 to $15 \%$. The total number of fibroblasts to be added to each mixture was calculated, and the density of the cortical cell suspension was adjusted so that the initial plating density remained constant. Seven flasks $\left(75 \mathrm{~cm}^{2}\right)$ were plated (six flasks for receptor binding and one flask for immunocytochemistry). The cultures were grown to confluency and were then prepared for either receptor binding assays or immunocytochemistry.

A series of experiments was designed to examine the effect of the initial cell plating density on the $\beta$-adrenergic receptor subtype present in cortical cultures. In these experiments, the cell suspension was diluted to 70,50 , 30 , or $10 \%$ of its original concentration. Seven flasks of each cell density were plated and grown to confluency, at which time they were assayed for receptor subtype and immunocytochemistry.

Immunocytochemistry. One flask from each astroglial cell culture that was to be examined for $\beta$-adrenergic receptor subtypes was set aside for double immunofluorescence staining. The upper portion of the flask was removed, and the cells were washed for 5 to $10 \mathrm{~min}$ with BME containing $25 \mathrm{mM}$ HEPES (BME-H, pH 7.2). Following a 10 -min fixation with $4 \%$ paraformaldehyde and $0.01 \%$ glutaraldehyde in phosphate-buffered saline (PBS, pH $7.2,4^{\circ} \mathrm{C}$ ) and a 5- to 10 -min wash with BME$H$, six to eight randomly placed circles were drawn on the culture surface with a wax pencil. By restricting subsequent steps to the areas enclosed by the wax circles, the cellular composition of the flasks could be examined using a minimum amount of antiserum $(25$ to $75 \mu \mathrm{l} /$ circle). Cells were first permeated with BME-H containing $10 \%$ fetal calf serum and $0.05 \%$ saponin (BME-HFCS-S) for $30 \mathrm{~min}$. Circled areas of the cell culture were then incubated for $30 \mathrm{~min}$ at room temperature with either normal rabbit serum or rabbit anti-GFAP (antibovine GFAP was donated by Dr. L. F. Eng; anti-human GFAP was purchased from Accurate) (1:50) diluted with BME-H-FCS-S. The cells were then rinsed twice with $\mathrm{BME}-\mathrm{H}$ and were incubated at room temperature in BME-H-FCS-S containing fluorescein-conjugated goat anti-rabbit $\operatorname{IgG}$ (Cappel) (1:50). Following another wash with $\mathrm{BME}-\mathrm{H}$, the cells were incubated with normal rabbit serum (1:10 in BME-H-FCS-S) for 30 min to reduce cross-reactivity. The cells were washed again with BME$\mathrm{H}$ for 5 to $10 \mathrm{~min}$ and were then incubated with rhodamine-conjugated goat anti-human fibronectin IgG (Cappel) (1:50) for $30 \mathrm{~min}$ at room temperature. The cells subsequently were washed with BME-H (5 to $10 \mathrm{~min}$ ) and were coverslipped with a 1:1 solution of PBS-glycerol. A Zeiss inverted microscope equipped wilh epifluorescence optics was utilized for cell counts and photography.

Quantitation of GFAP and fibronectin staining. Five of the areas that had been stained for GFAP and fibronectin were counted per flask. Within each circled area, 20 nonoverlapping fields were examined for specific rhodamine or fluorescein fluorescence using a $40 \times$ objective. Each field was scored by assessing whether one-fourth, one-half, three-fourths, or all of the field visible contained specific staining. The total counts were tallied and were expressed as the number of fields per 100 that exhibited either GFAP or fibronectin staining.

Preparation of membranes. The medium was aspirated from culture flasks, and the cells were washed twice with $10 \mathrm{ml}$ of ice-cold $1 \mathrm{mM}$ Tris $(\mathrm{pH} \mathrm{7.5)}$. After incubation for $15 \mathrm{~min}$ on ice, the swollen cells were lysed and suspended by scraping the flasks with a rubber policeman. The cell lysates were centrifuged $(35,000 \times \mathrm{g}, 15$ $\min , 4^{\circ} \mathrm{C}$ ), and the particulate fraction was resuspended in $1 \mathrm{ml}$ of $0.25 \mathrm{M}$ sucrose, $1 \mathrm{mM} \mathrm{MgCl}_{2}$, and $20 \mathrm{mM}$ Tris $(\mathrm{pH} 7.5)$ and stored at $-70^{\circ} \mathrm{C}$ until used in the assay. Storage had no detectable effect on the number or properties of $\beta$-adrenergic receptors.

$\beta$-Adrenergic receptor assay. (-)-Cyanopindolol (CYP) and (-)-pindolol (PIN) were iodinated as previously described (Witkin and Harden, 1981), and the iodinated derivatives $\left[{ }^{125}\right.$ I]CYP and $\left[{ }^{125} I\right]$ PIN were utilized to label receptors in membrane preparations. Receptor assays were carried out by incubating membrane fractions $(30$ to $50 \mu \mathrm{g}$ of protein) in $20 \mathrm{mM}$ Tris buffer $(\mathrm{pH} 7.5$ at $37^{\circ} \mathrm{C}$ ) containing $154 \mathrm{mM} \mathrm{NaCl}, 5 \mathrm{mM} \mathrm{MgCl}_{2}$, 55 to 60 $\mathrm{pM}\left[{ }^{125} \mathrm{I}\right] \mathrm{CYP}$ or 90 to $100 \mathrm{pM}\left[{ }^{125} \mathrm{I}\right] \mathrm{PIN}$, and various concentrations of metoprolol or ICI 118,551 for $60 \mathrm{~min}$ at $37^{\circ} \mathrm{C}\left(\left[{ }^{125} \mathrm{I}\right] \mathrm{CYP}\right)$ or $25^{\circ} \mathrm{C}\left(\left[{ }^{125} \mathrm{I}\right] \mathrm{PIN}\right)$ in a total volume of $0.25 \mathrm{ml}$. The concentrations of $\left[{ }^{125} \mathrm{I}\right] \mathrm{CYP}$ or $\left[{ }^{125} \mathrm{I}\right] \mathrm{PIN}$ in competition binding experiments were well in excess of their $K_{d}$ values and the concentration of receptors. Thus, in all experiments less than $5 \%$ of the total radioligand was bound. Identical results were obtained with each radioligand. The reaction was terminated by addition of $10 \mathrm{ml}$ of $10 \mathrm{mM}$ Tris buffer $\left(\mathrm{pH} 7.5\right.$ at $\left.37^{\circ} \mathrm{C}\right)$ containing $154 \mathrm{mM} \mathrm{NaCl}$ followed by filtration through glass fiber filters (Schleicher and Schuell \#30). Each filter was washed with an additional $10 \mathrm{ml}$ of the same buffer. Radioactivity on the filters was determined in a gamma counter at an efficiency of $70 \%$. Nonspecific binding was defined as the amount of radioligand bound in the presence of $100 \mu \mathrm{M}$ isoproterenol. Specific binding represented 80 to $95 \%$ of the radioactivity retained by the filters. Assays were carried out in triplicate. Unless otherwise stated, competition curves shown are those obtained using $\left[{ }^{125} \mathrm{I}\right] \mathrm{CYP}$.

In some experiments, membrane fractions derived from purified cultures of astroglia and meningeal cells were incubated with various concentrations $(0.2$ to 70 $\mathrm{pM}$ ) of $\left.{ }^{125} \mathrm{I}\right] \mathrm{CYP}$ for $90 \mathrm{~min}$ at $37^{\circ} \mathrm{C}$ in a total volume of $1 \mathrm{ml}$. The amount of radioligand specifically bound at each concentration, which represented less than $5 \%$ of the total radioligand, was determined as described above. These data were analyzed by the method of Scatchard (1949) to provide estimates for the number of receptors and the dissociation constant of $\left[{ }^{125} \mathrm{I}\right] \mathrm{CYP}$.

Protein assay. Protein concentration was determined by the method of Lowry et al. (1951) using bovine serum albumin as a standard.

Data analysis. Analysis and interpretation of the binding of $\beta$-adrenergic receptor subtype selective and nonselective agents were made using the assumptions that have been discussed previously (Minneman et al., 1979a, b; Homburger et al., 1981; DeLean et al., 1982). Namely, (1) there are only two $\beta$-adrenergic receptor subtypes; (2) metoprolol and ICI 118,551 are $\beta_{1}$ - and $\beta_{2}$-adrenergic 
receptor subtype selective antagonists, respectively; and (3) the interaction of each antagonist with either receptor subtype can be modeled by simple law of mass action isotherms.

Competition curves were analyzed by nonlinear leastsquares curve fitting of the raw data using the GaussNewton method (SAS, 1979). The model used was that for law of mass action interaction of the competing ligand with either a single site $(n=1)$ or two independent sites $(n=2)$ as follows:

$$
B_{s}=\sum_{i=1}^{n}\left(B_{i}-\frac{B_{i} S}{I C_{50 i}+S}\right)+N S
$$

where $S$ is the concentration of competing ligand, $B_{s}$ is the $\left[{ }^{125} \mathrm{I}\right] \mathrm{CYP}$ bound at a given value of $S, B_{l}$ is the number of specific binding sites, $\mathrm{IC}_{50 i}$ is the concentration of the competing ligand that inhibits specific radioligand binding by $50 \%$ at each binding site, and NS is the number of nonspecific sites. Using $4 \mathrm{pM}$ as the $K_{d}$ of $\left[{ }^{125} \mathrm{I}\right] \mathrm{CYP}$ at both $\beta_{1}$ - and $\beta_{2}$-adrenergic receptors, the Cheng-Prusoff approximation was utilized to convert derived $\mathrm{IC}_{50}$ values to $K_{i}$ values. To determine if the data were fit significantly better by the two-site model, the residual sums of squares of the respective fits were compared using a partial $F$ test (DeLean et al., 1982). In all figures, the curve drawn is that for the derived fit of the data to the appropriate model, while the points represent the means of triplicate experimental values.

\section{Results}

$\Lambda$ s shown in Figure 1 $1,\left[{ }^{125} \mathrm{I}\right] \mathrm{CYP}$ bound with high affinity $\left(K_{d}=4.4 \pm 0.4 \mathrm{pM}, n=4\right)$ to membranes prepared from cerebral cortical astroglial cultures (Fig. $4, A$ to $C$, consists of micrographs that illustrate the appearance of these cultures by phase contrast and immunofluorescence staining with GFAP and with fibronectin). Similarly (Fig. $1 B$ ), $\left[{ }^{125}\right.$ I]CYP bound with high affinity to membranes from meningeal fibroblast cultures ( $K_{d}=3.4 \pm 0.2 \mathrm{pM}, n=5$ ). Since rat cerebral cortical astroglia (Harden and McCarthy, 1982) and meningeal fibroblasts (Ebersolt et al., 1981a, b) have been shown previously to express $\beta_{1}$ - and $\beta_{2}$-adrenergic receptors, respectively, these data indicate that $\left[{ }^{125} \mathrm{I}\right] \mathrm{CYP}$ exhibited little selectivity for $\beta$-adrenergic receptor subtypes. This conclusion is consistent with that made previously by Engel et al. (1981). The maximal binding capacity for $\left[{ }^{125} \mathrm{I}\right] \mathrm{CYP}$ in membranes from astroglial cultures $(47.5 \pm$ $4.3 \mathrm{fmol} / \mathrm{mg}$ of protein) was routinely 2 - to 3 -fold higher than that exhibited by membranes from meningeal fibroblasts $(22.8 \pm 0.7 \mathrm{fmol} / \mathrm{mg}$ of protein).

Using membranes derived from standard cortical astroglial cultures (see Fig. 4, $A$ to $C$ for staining pattern), competition binding curves (Fig. 2) were generated for metoprolol (a $\beta_{1}$-adrenergic receptor selective antagonist) and ICI 118,551 (a $\beta_{2}$-adrenergic receptor selective antagonist). The $K_{i}$ values calculated for the two drugs were similar to those calculated for metoprolol ( $64 \mathrm{nM})$ and ICI 118,551 (62 $\mathrm{nM})$ at $\beta_{1}$-adrenergic receptors in a previous study (Harden and McCarthy, 1982), and the Hill slopes of each of these curves were approximately unity. The displacement of $\left.{ }^{125} \mathrm{I}\right] \mathrm{CYP}$ by either antagonist was not significantly better fit by a two-site model.

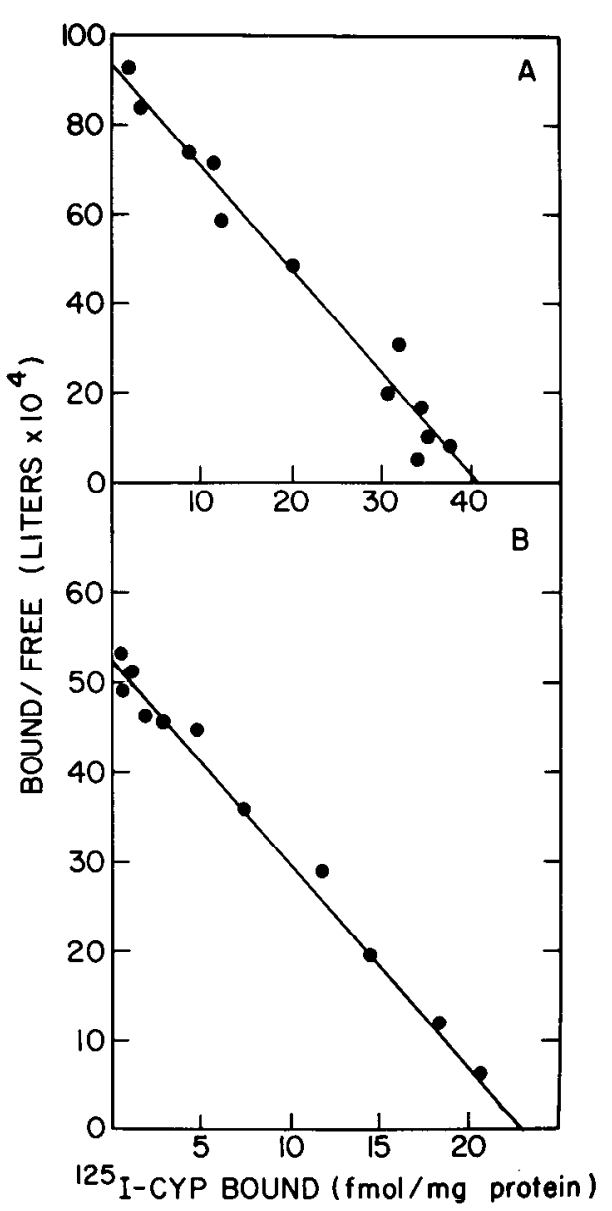

Figure 1. Scatchard analysis of $\left[{ }^{125} \mathrm{I}\right] \mathrm{CYP}$ binding to cortical astroglia $(A)$ and meningeal fibroblasts $(B)$. Membranes were incubated with various concentrations of $\left[{ }^{125} \mathrm{I}\right] \mathrm{CYP}$ as described under "Materials and Methods." The amount of radioligand bound is plotted against the quotient of radioligand bound divided by free $\left[{ }^{125} \mathrm{I}\right] \mathrm{CYP}$ concentration. The $K_{d}$ value was 4.38 pM for astroglia $(A)$ and $4.42 \mathrm{pM}$ for meningeal fibroblasts $(B)$. The $B_{\max }$ value was $40.7 \mathrm{fmol} / \mathrm{mg}$ of protein for astroglia and $23.4 \mathrm{fmol} / \mathrm{mg}$ of protein for meningeal fibroblasts. The data are representative of Scatchard plots obtained with four to five separate preparations of cerebral cortical astroglia and meningeal fibroblasts.

This was interpreted to indicate the presence of a homogeneous population of high affinity metoprolol, low affinity ICI 118,551 binding sites (i.e., $\beta_{1}$-adrenergic receptors). Photomicrographs of the immunocytochemical staining of this preparation are shown in Figure $4, A$ to C. Quantitative analysis of the composition of this astroglial cell culture confirmed that 97 of 100 fields were GFAP-positive (Table I).

The competition curves for metoprolol and ICI 118,551 for membranes prepared from meningeal fibroblast cultures (Fig. $3 D$ ) were very different from those obtained with astroglial cells (Fig. 2), and the $K_{i}$ values calculated for these two drugs (metoprolol-2.04 $\mu \mathrm{M}$; ICI 118,551$1.1 \mathrm{nM}$ ) were similar to those reported previously for $\beta_{2}$ adrenergic receptors (Harden and McCarthy, 1982). Immunocytochemical analysis of standard meningeal cell cultures confirmed that virtually every field was positive for fibronectin, and no significant amount of GFAP staining could be detected (see Fig. $8, A$ to $C$ ). 
Thus, using immunocytochemically defined rat cerebral cortical and meningeal cultures, the $\beta$-adrenergic receptor subtype expressed by astroglial cells apparently is $\beta_{1}$, whereas the subtype expressed by meningeal fibroblasts is $\beta_{2}$. However, the primary impetus for this work was to establish the validity of a combined immunocytochemical-receptor assay approach for defining cellspecific receptor distribution. Thus, it was important to assess quantitatively both immunocytochemical staining and receptor subtypes under conditions where the proportion of specific cell populations in cortical cell cultures was differentially modified. One approach utilized was to examine the influence of fibroblast contamination on the estimated proportion of $\beta_{2}$-adrenergic receptors present in cortical astroglial cultures. Thus, fibroblasts were added in various amounts to initial cortical cell suspensions and plated into flasks as described under "Materials and Methods." Competition binding curves for metoprolol and ICI 118,551 are illustrated for four such mixtures

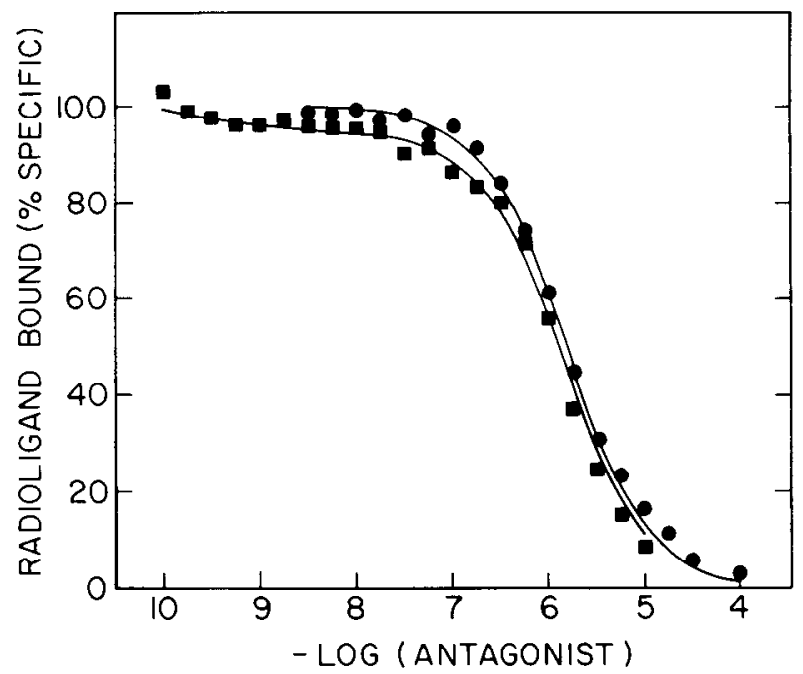

Figure 2. Competition binding curves for the $\beta$-adrenergic receptor subtype selective drugs metoprolol (circles) and ICI 118,551 (squares) with membranes from a cortical astroglial culture. Membranes were incubated with $98 \mathrm{pM}\left[{ }^{125} \mathrm{I}\right] \mathrm{CYP}$ and various concentrations of the indicated drugs.
(Fig. 3, $A$ to $D$ ). The deviation of curves from that observed for pure astroglia (Fig. 2) increased in cultures prepared from cell suspensions containing increasing numbers of fibroblasts (Fig. $3, A$ to $C$ ). Competition curves generated from cultures that had a low percentage of fibroblasts added (Fig. 3A) were similar to those obtained with the astroglial preparation (Fig. 2). In contrast, cultures supplemented with large numbers of fibroblasts (Fig. 3, $B$ and $C$ ) generated competition curves approaching those obtained for meningeal cells (Fig. $3 D$ ). The estimated percentages of $\beta$-adrenergic receptor subtypes and immunocytochemical markers in these cultures are presented in Table I. Modeling of the data indicated that approximately $90 \%$ of the receptors were of the $\beta_{1}$-subtype in a preparation that had few fibroblasts added to the initial cell suspension. Virtually all of the cells exhibited specific GFAP staining, while only a few fine strands of fibronectin-positive staining could be identified (Fig. 5, $A$ to $C$ ). As the number of fibroblasts added to the initial cell suspension increased, the proportion of the culture that stained with fibronectin increased as did the estimated percentages of $\beta_{2}$-adrenergic receptors (Figs. 6, $A$ to $C$, and $7, A$ to $C$ ). At the other extreme (Fig. $3 D$ ), the modeling of competition curves derived from meningeal cell cultures reflected the presence of virtually a pure population of $\beta_{2}$-adrenergic receptors (Table I). Furthermore, less than 3 of 100 fields contained GFAP staining, whereas 98 of 100 fields were fibronectin-positive (see Table I and Fig. 8, $A$ to $C$ for photomicrographs). Finally, the cultures from which the dala in Figure $3, B$ and $C$ were derived expressed significant levels of both $\beta_{1}$ - and $\beta_{2}$-adrenergic receptors and a similar presence of GFAP-positive and fibronectinpositive fields (Figs. $6, A$ to $C$, and $7, A$ to $C$ ). Taken together, this series of competition binding curves and immunocytochemical staining suggest that an increase in the number of $\beta_{2}$-adrenergic receptors can be correlated with an increase in fibronectin-positive staining cells in the cultures.

One aspect of astroglial culture preparation that varies among laboratories is the initial cell plating density. In a previous report (Harden and McCarthy, 1982), it was suggested that preparation of astroglial cultures using

TABLE I

Quantitation of $\beta$-adrenergic receptor subtypes and immunocytochemical markers in mixed cultures of astroglia and meningeal fibroblasts

Cultures were prepared with various ratios of astroglia to fibroblasts in the initial plating (see "Materials and Methods"). Analysis of the competition curves illustrated in Figures 2 and $3, A$ to $D$ were carried out as described under "Materials and Methods." The estimated percentage of each receptor subtype is presented for the competition curves generated for each competing ligand. The competition curves for preparation 1 are shown in Figure $2 A$. The competition curves for preparations 2 to 5 are shown in Figure $3, A$ to $D$, respectively. The number of fields per 100 expressing GFAP or fibronectin staining in the same cultures also is presented. The immunocytochemical staining of typical fields from preparations 1 to 5 are shown in Figures 4 to 8, respectively. The data are representative of three similar experiments.

\begin{tabular}{|c|c|c|c|c|}
\hline Preparation & $\begin{array}{c}\text { Percentage of } \\
\beta_{1} \text {-Adrenergic } \\
\text { Receptors }\end{array}$ & $\begin{array}{c}\text { Percentage of } \\
\beta_{2} \text {-Adrenergic }{ }^{a} \\
\text { Receptors }\end{array}$ & GFAP $^{b}$ & Fibronectin $^{b}$ \\
\hline glial & $100 / 100$ & $0 / 0$ & 97 & 3 \\
\hline d astroglial/fibroblast & $87 / 90$ & $13 / 10$ & 81 & 56 \\
\hline d astroglial/fibroblast & $79 / 79$ & $21 / 21$ & 62 & 50 \\
\hline d astroglial/fibroblast & $35 / 49$ & $65 / 51$ & 32 & 75 \\
\hline blast & $0 / 11^{c}$ & $100 / 89$ & 3 & 98 \\
\hline
\end{tabular}

\section{Astroglial}

2. Mixcd astroglial/fibroblast

3. Mixed astroglial/fibroblast

4. Mixed astroglial/fibroblast

5. Fibroblast

a The top number was obtained using metoprolol; the bottom number was obtained using ICI $118,551$.

${ }^{u}$ Expresed as the number of fields of 100 that exhibited specific staining.

${ }^{c}$ The displacement of $\left[{ }^{125} \mathrm{I}\right] \mathrm{CYP}$ by metoprolol was not modeled significantly better by the inclusion of a second site; the $K_{i}$ of the single-site model was that of a $\beta_{2}$-adrenergic receptor. 


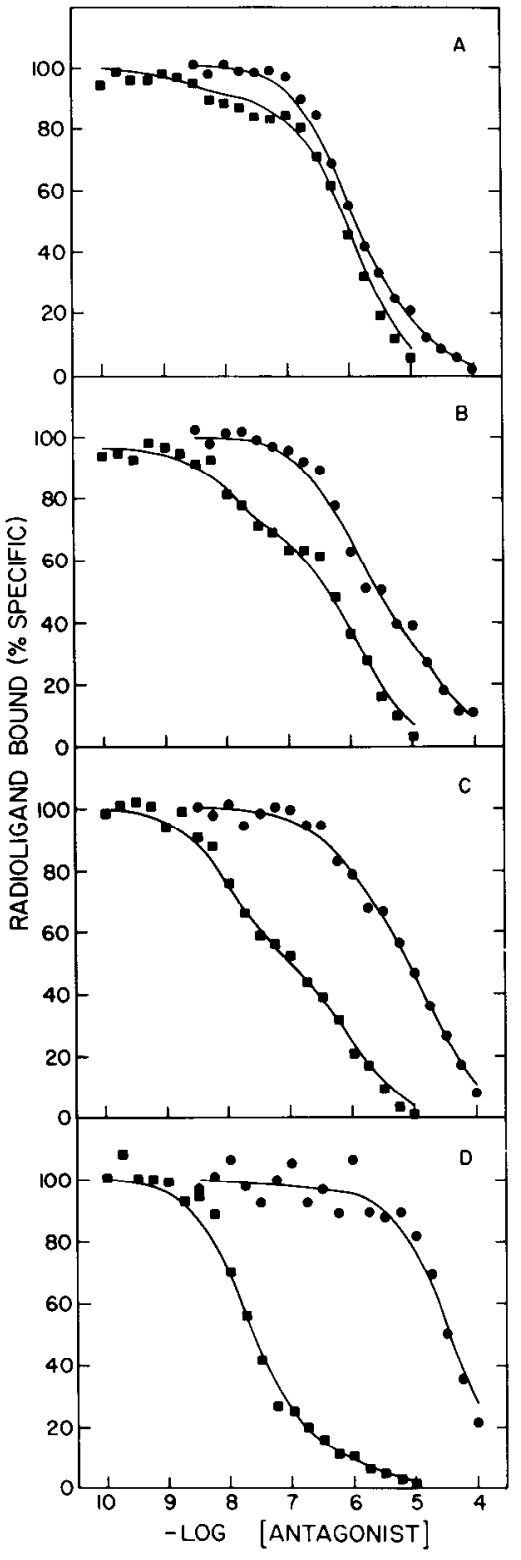

Figure 3. Competition binding curves with membranes from cortical astroglial cultures that had been purposely contaminated with meningeal fibroblasts. Mixed cultures of astroglia and meningeal fibroblasts were prepared as described under "Materials and Methods." Data are presented for cultures that had minimal fibroblast contamination $(A)$, for cultures with increasing fibroblast contamination ( $B$ and $C$ ), and for cultures that consisted almost entirely of fibroblasts $(D)$. Estimated percentages of $\beta$-adrenergic receptor subtypes from these curves are presented in Table I. Membranes were incubated with 60 pM $\left[{ }^{125} \mathrm{I}\right] \mathrm{CYP}$ and various concentrations of metoprolol (circles) and ICI 118,551 (squares). The data are representative of three similar experiments. In all figures the curve drawn is that for the derived fit of the data to the appropriate model, while the points represent the means of triplicate experimental values.

low initial seeding densities increased the proportion of $\beta_{2}$-adrenergic receptors. This possibility was examined by preparing cultures of various initial seeding densities which were then grown to confluency and analyzed for receptor subtype and immunocytochemical staining. Modeling of competition curves generated with the typical astroglial preparation estimated that $93 \%$ of the receptors were $\beta_{1}$, while $7 \%$ or less were $\beta_{2}$ (Fig. 9A). Similarly, analysis of the same culture stained with GFAP and fibronectin suggested that the majority of the cells present in the culture were astroglia (89 fields of 100 were GFAP-positive), although 30 fields of 100 did have fibronectin-positive staining. The effect of diluting the concentration of the original cell suspension by 10 fold is shown in Figure $9 B$. Under this condition modeling of the data indicated that $83 \%$ of the receptors in confluent cultures were $\beta_{1}$ and $17 \%$ were $\beta_{2}$. A similar change in the proportion of the culture staining for GFAP and fibronectin was found. While 77 of 100 fields were positive for GFAP in cultures prepared from the diluted cell suspension, 49 of 100 fields were positive for fibronectin. Thus, dilution of the original suspension decreased the number of astroglial cells present and increased the number of fibroblasts and increased the proportion of $\beta_{2}$-adrenergic receptors present in the cultures.

As illustrated in Figure 10, competition curves generated from "astroglial" cultures prepared from animals 6 days after birth were markedly different from those of the standard astroglial preparation (Fig. 2). Modeling of the curves indicated that only $74 \%$ of the $\beta$-adrenergic receptors were $\beta_{1}$, whereas $26 \%$ were $\beta_{2}$. Immunocytochemical analysis of similar cultures indicated that there was a comparable reduction in GFAP and an increase in fibronectin staining (data not shown).

\section{Discussion}

The results presented in this study confirm previous observations by Harden and McCarthy (1982) that the $\beta$-adrenergic receptor subtype expressed by astroglial cultures prepared from neonatal rat cerebral cortex is $\beta_{1}$. Furthermore, our results suggest that the principal source of $\beta_{2}$-receptors in cortical astroglial cultures is contamination by meningeal fibroblasts. Several lines of evidence support this contention. First, modeling of competition binding curves indicated that the $\beta$-adrenergic receptor subtype of cortical astroglial cultures that exhibited little or no fibronectin staining was almost exclusively $\beta_{1}$. Similarly, the receptor subtype characteristic of confluent cultures of meningeal fibroblasts that stained positively with fibronectin and contained only minimal amounts of GFAP staining was $\beta_{2}$. The correlation of $\beta_{2}$-adrenergic receptors with the presence of fibroblasts in astroglial cell cultures was further established by examining the effect of adding meningeal fibroblasts to suspensions of cerebral cortical cells prior to plating. Characterization of various mixed fibroblastcortical cell cultures by immunocytochemistry and radioligand binding assays confirmed that both fibronectin staining and the expression of $\beta_{2}$-adrenergic receptors increased, while GFAP staining and the percentage of $\beta_{1}$-adrenergic receptors decreased when increasing numbers of fibroblasts were added.

These observations suggest that the presence of fibroblasts in an astroglial cell culture can be correlated with the presence of $\beta_{2}$-adrenergic receptors. Consequently, any modification in culture methodology that encourages the proliferation of fibroblasts can be expected to shift 

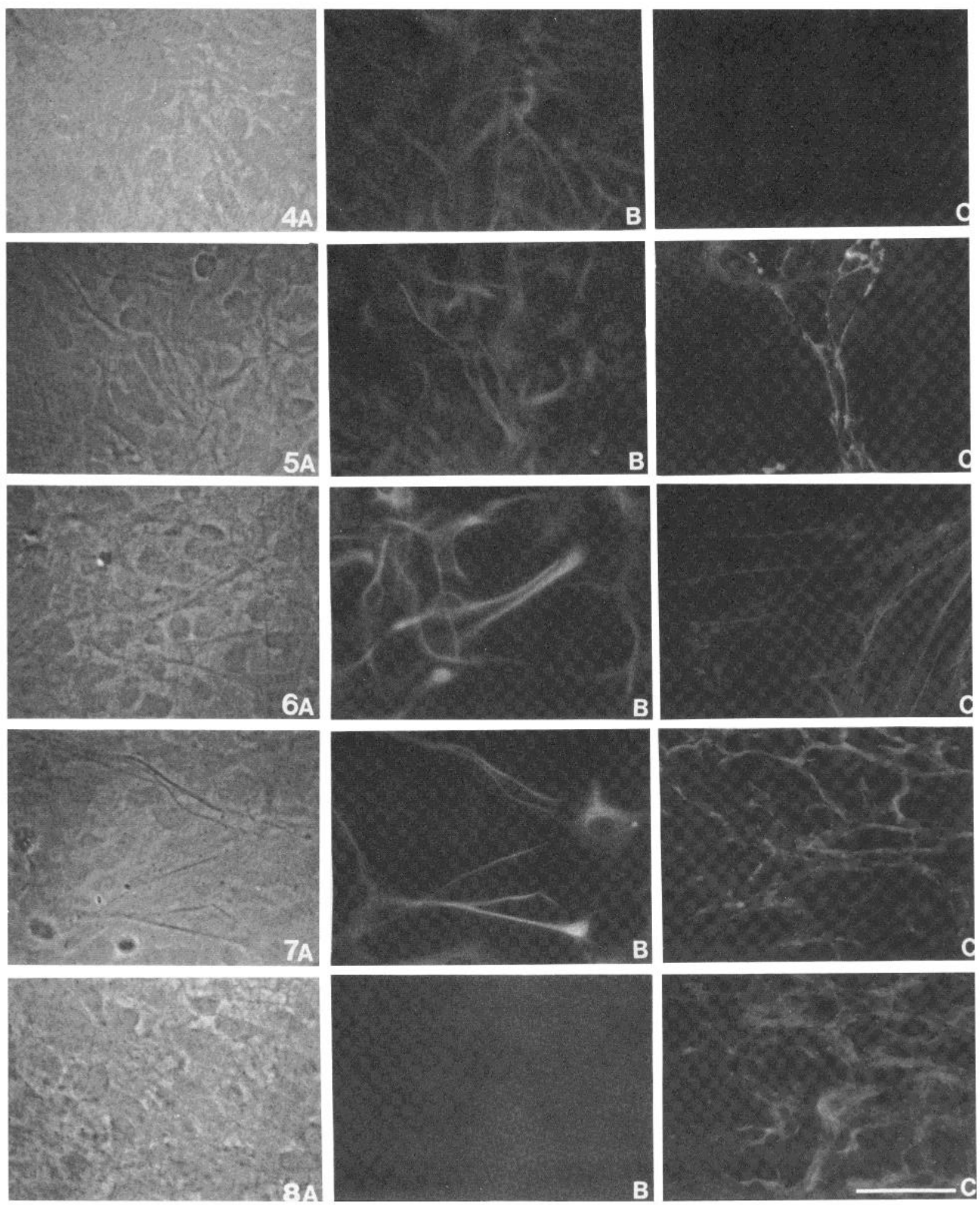

Figures 4 to 8 . These figures illustrate the appearance of the purified and mixed astroglial and meningeal cultures used to generate the competition binding curves shown in Figures 2 and $3, A$ to $D$, respectively. The scale bar is $100 \mu \mathrm{m}$.

Figure 4. The phase contrast appearance of a typical field in the culture used to generate the competition curves in Figure 2. Virtually all of the field is stained positively with GFAP $(B)$, whereas no specific fibronectin staining $(C)$ is present.

Figure 5. The phase contrast appearance of a typical field in the culture used to generate the competition curves in Figure $3 A$. Although GFAP $(B)$ staining is present over the entire field, several strands of specific fibronectin staining $(C)$ can be seen.

Figure 6. The phase contrast $(A)$ and fluorescent appearance of GFAP $(B)$ and fibronectin $(C)$ staining of a single field in the culture used for the competition binding curves shown in Figure $3 B$. The amount of GFAP staining is reduced, while the amount of fibronectin staining has increased.

Figure 7. These three photomicrographs illustrate the phase contrast $(A)$, GFAP-stained $(B)$, and fibronectin-stained $(C)$ appearance of the culture used to generate the competition binding curve shown in Figure $3 C$. Only a few cells stained positively for GFAP, whereas specific fibronectin staining can be seen throughout the field.

Figure 8. Phase contrast $(A)$ and fluorescent micrographs of GFAP $(B)$ and fibronectin $(C)$ staining of a single field in the culture used to prepare the competition binding curves shown in Figure $3 D$. No specific GFAP staining is apparent, whereas virtually the entire field exhibits specific fibronectin staining. 


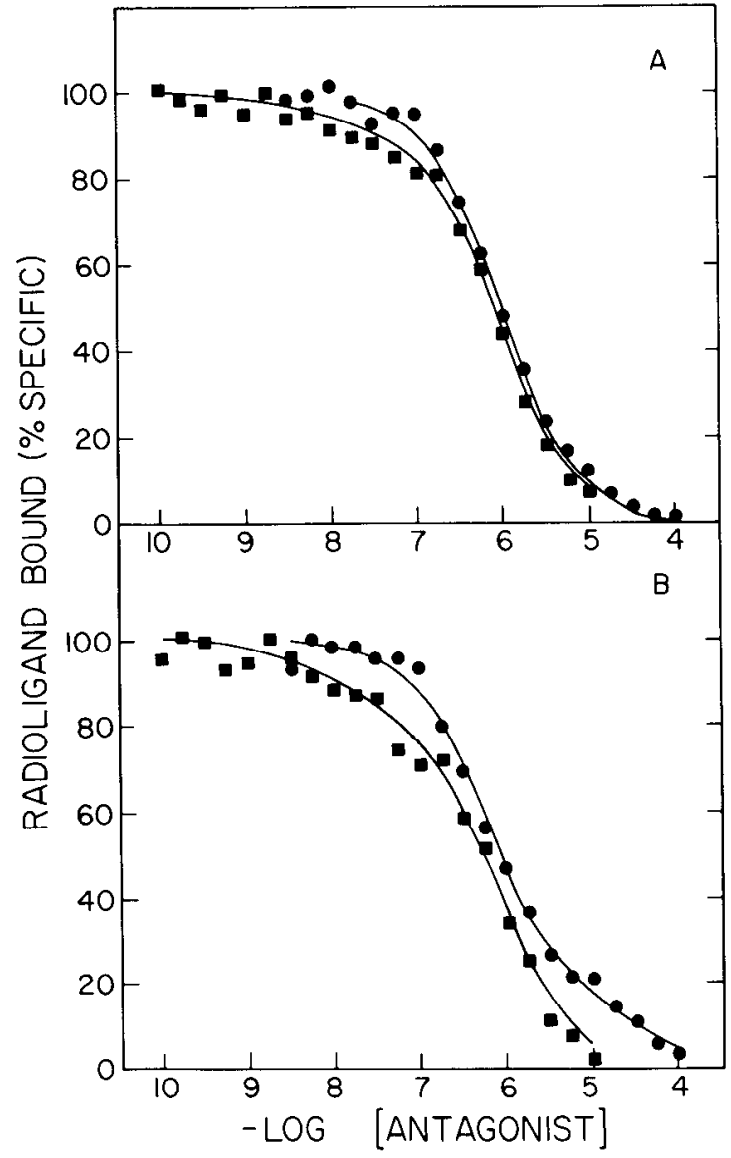

Figure 9. Effect of cell plating density on the expression of $\beta$-adrenergic receptor subtypes. Competition binding curves for the $\beta$-adrenergic receptor subtype selective drugs metoprolol (circles) and ICI 118,551 (squares) were generated with membranes from an astroglial culture seeded at the standard density (A) as described under "Materials and Methods" and a similar culture plated from the same suspension that had been diluted 10 -fold $(B)$. Membranes were incubated with $56 \mathrm{pM}\left[{ }^{125} \mathrm{I}\right] \mathrm{CYP}$ and various concentrations of the competing drugs. These data are representative of two similar experiments.

the proportion of $\beta$-adrenergic receptors in "astroglial cultures" toward the $\beta_{2}$-subtype. One such aspect of culture preparation is the initial seeding density. A high initial seeding density would provide little opportunity for a highly proliferative cell type, such as the fibroblast, to overrun the culture. However, if the initial cell density is low, cells that can proliferate rapidly will become more numerous and subsequently alter the proportion of cell types. Our findings indicate that dilution of the initial cell suspension by 10 -fold resulted in a 2- to 4 -fold increase in the degree of fibroblast contamination (as indicated by fibronectin staining) and in the percentage of $\beta_{2}$-adrenergic receptors. Furthermore, when less care was taken in removing the meninges, astroglial cultures prepared from dilute cortical cell suspensions exhibited an even more extensive fibroblast overgrowth and a more substantial increase in $\beta_{2}$-adrenergic receptors (P. A. Trimmer and K. D. McCarthy, unpublished observations). Since the initial cell plating density used by Ebersolt et al. (1981a, b) was only one-third to onefourth of that used in our studies, this difference in culture preparation may account in part for the high proportion of $\beta_{2}$-receptors found in their cultures.

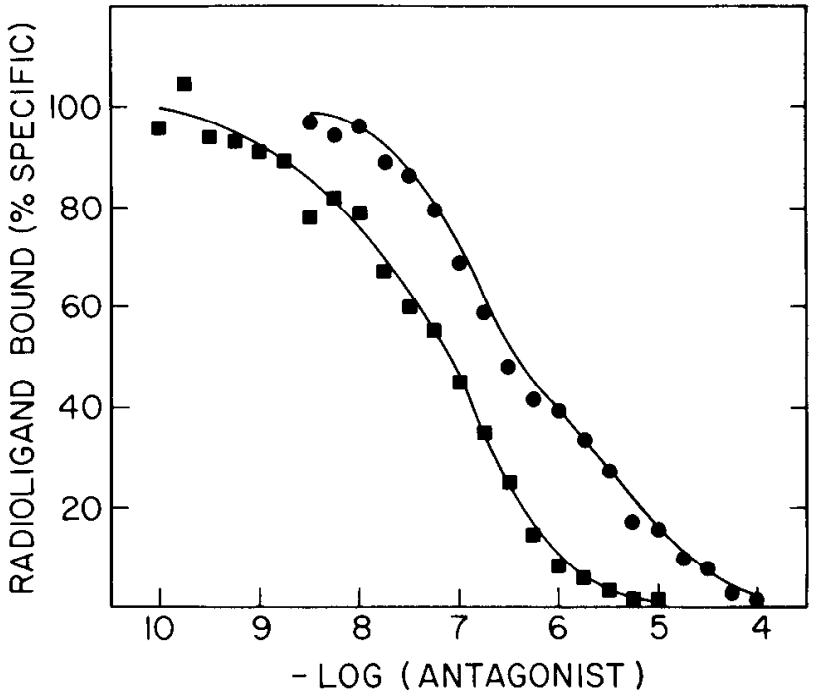

Figure 10. Competition binding curves with membranes from a cortical astroglial culture prepared from rats 6 days postnatal. Membranes were incubated with $104 \mathrm{pM}\left[{ }^{125} \mathrm{I}\right]$ pindolol and various concentrations of metoprolol (circles) and ICI 118,551 (squares). These data are representative of five similar experiments.

Another aspect of culture preparation that can alter the expression of $\beta$-adrenergic receptor subtypes is the age of the animal used to establish the culture. Cortical cell cultures prepared from 6-day-old animals contained a high percentage of $\beta_{2}$-adrenergic receptors and exhibited an equally large amount of fibronectin staining. These results are consistent with the observation that the yield of astroglia is markedly reduced when cultures are prepared from older animals (P. A. Trimmer and K. D. McCarthy, unpublished observations). Furthermore, it becomes increasingly difficult to remove all of the meninges. These factors favor the growth of highly proliferative fibroblasts.

One aspect of this study that merits further discussion is the use of combined immunocytochemical staining and radioligand binding to establish receptor localization on specific cell types. Primary cell cultures are subject to considerably more variation than the clonal cell lines of supposed neural origin commonly used for receptor studies (Clark and Perkins, 1971; Pfeiffer et al., 1977). The variation from culture to culture within a laboratory and between laboratories can be substantial. Therefore, it is essential to be able to assess consistently, both quantitatively and qualitatively, the cellular composition of cultures used for receptor or other biochemical studies. Ebersolt et al. (1981a, b) used GFAP staining alone to characterize astroglial cultures used for studies of radioligand binding and $\beta$-adrenergic receptor-stimulated adenylate cyclase activity. Since $95 \%$ of the cells in their cultures stained positively for GFAP, they concluded that the $\beta_{2}$-adrenergic receptors detected must be located on astrocytes, not fibroblasts. However, as demonstrated here and elsewhere (Steig et al., 1980), the use of only GFAP antibody staining as a measure of astroglial culture composition can result in an overestimation of purity. This is primarily due to the fact that fibroblasts tend to overgrow astroglia and are extremely difficult to detect by phase microscopy or with immunofluorescence staining using GFAP alone. Double staining with both 
GFAP and fibronectin revealed that substantial amounts of fibronectin could be found even in cultures that appeared to contain only astroglia. Although fibronectin staining in combination with GFAP staining is valuable for detecting the presence of fibroblasts in astroglial cultures, several drawbacks must be faced in quantification of fibronectin staining. First, unlike GFAP, which is an intracellular protein, fibronectin is secreted by fibroblasts and deposited at sites of cell attachment to the substratum or to other cells. Although fibronectin staining can be clearly associated with individual cells in nonconfluent cultures, it forms a complex filamentous meshwork branching between and over cells in confluent cultures. Thus, quantification of fibronectin staining is biased by the diffuse pattern of staining and is difficult to measure on a per cell basis in confluent cultures. This may be one reason why the proportion of cultures that stained positively for fibronectin was consistently 2 to 4 times higher than the levels that might be anticipated on the basis of the density of $\beta_{2}$-adrenergic receptors. In addition, it is important to point out that the density of $\beta_{2}$-adrenergic receptors on fibroblasts appeared to be less than the level of $\beta_{1}$-adrenergic receptors expressed by astroglia. This difference in receptor number may also contribute to the disparity between fibronectin staining and the proportion of receptors of the $\beta_{2}$-subtype. Indeed, this difference in receptor density on astroglia versus fibroblasts was used previously to support the contention that fibroblast contamination does not contribute significantly to the $\beta_{2}$-adrenergic receptor population in astroglial cell cultures (Ebersolt et al., 1981b). Although the studies described in the current work argue strongly in favor of fibroblasts being the source of $\beta_{2}$-adrenergic receptors in astroglial cell cultures, they do not eliminate the possibility that a subpopulation of astroglia express the $\beta_{2}$-adrenergic receptor subtype.

In conclusion, this study presents a combined immunocytochemical-receptor assay approach for defining receptor and cell populations in cerebral cortical cultures which has been used successfully to determine the subtype of $\beta$-adrenergic receptors expressed by cortical astroglia in vitro. This approach, in combination with newly developed autoradiographic methodology for identifying receptors on single cells (McCarthy, 1983), should prove very useful for furthering our understanding of the mechanisms through which neurons and glia communicate.

\section{References}

Clark, R. B., and J. P. Perkins (1971) Regulation of adenosine $3^{\prime}: 5^{\prime}$-cyclic monophosphate concentration in cultured human astrocytoma cells by catecholamines and histamine. Proc. Natl. Acad. Sci. U. S. A. 68: 2757-2760.

DeLean, A., A. A. Hancock, and R. J. Lefkowitz (1982) Validation and statistical analysis of a computer modeling method for quantitative analysis of radioligand binding data for mixtures of pharmacological receptor subtypes. Mol. Pharmacol. 21: 5-16.

Ebersolt, C., M. Perez, and J. Bockaert (1981a) Neuronal, glial and meningeal localizations of neurotransmitter-sensitive adenylate cyclases in cerebral cortex of mice. Brain Res. 213: $139-150$.

Fhersolt, C., M. Perez, G. Vassent, and .J. Rockaert (1981b) Characteristics of the $\beta_{1}$ - and $\beta_{2}$-adrenergic sensitive adenyl- ate cyclases in glial ccll primary cultures and their comparison with $\beta_{2}$-adrenergic sensitive adenylate cyclase of meningeal cells. Brain Res. 213: 151-161.

Engel, G., D. Hoyer, R. Berhold, and H. Wagner (1981) (+/-)$\left({ }^{125}\right.$ Iodo)-cyanopindolol, a new ligand for $\beta$-adrenoceptors in guinea pig. Naunyn-Schmiedeberg's Arch. Pharmacol. 317: $277-285$.

Evans, T., P. A. Trimmer, K. D. McCarthy, and T. K. Harden (1983) Identification of receptors on highly purified, immunocytochemically defined primary cultures of astroglia. In Fifth International Congress on Cyclic Nucleotides and Protein Phosphorylation, in press.

Friedman, A. H., and J. N. Davis (1980) Identification and characterization of adrenergic receptors and catecholaminestimulated adenylate cyclase in hog pial membranes. Brain Res. 183: 89-102.

Harden, T. K., and K. D. McCarthy (1982) Identification of the beta adrenergic receptor subtype on astroglia purified from rat brain. J. Pharmacol. Exp. Ther. 222: 600-605.

Homburger, V., M. Lucas, E. Rosenbaum, G. Vassent, and J. Rockaert (1981) Presence of both beta ${ }_{1}$ - and beta $a_{2}$-adrenergic receptors in a single cell type. Mol. Pharmacol. 20: 403-409.

Lowry, O. H., N. J. Rosebrough, A. L. Farr, and R. J. Randall (1951) Protein measurement with Folin phenol reagent. J. Biol. Chem. 193: 265-275.

McCarthy, K. D. (1983) An autoradiographic analysis of $\beta$ adrenergic receptors on immunocytochemically defined astroglia. J. Pharmacol. Exp. Ther. 226: 282-290.

McCarthy, K. D., and J. de Vellis (1978) Alpha-adrenergic modulation of beta-adrenergic, adenosine and prostaglandin $\mathrm{E}_{1}$ increased adenosine $3^{\prime}, 5^{\prime}$-cyclic monophosphate levels in primary cultures of glia. J. Cyclic Nucleotide Res. 4: 15-26.

McCarthy, K. D., and J. de Vellis (1980) Preparation of separate astroglial and oligodendroglial cell cultures from rat cerebral tissue. J. Cell Biol. 85: 890-902.

McCarthy, K. D., and T. K. Harden (1981) Identification of two benzodiazepine binding sites on cells cultured from the rat cerebral cortex. J. Pharmacol. Exp. Ther. 216: 183-191.

Minneman, K. P., A Hedberg, and P. B. Molinoff (1979a) Comparison of beta adrenergic receptor subtypes in mammalian tissues. J. Pharmacol. Exp. Ther. 211: 502-508.

Minneman, K. P., L. R. Hegstrand, and P. B. Molinoff (1979b) Simultaneous determination of beta- 1 and beta- 2 adrenergic receptors in tissues containing both receptor subtypes. Mol. Pharmacol. 16: 34-46.

Minneman, K. P., M. D. Dibner, B. B. Wolfe, and P. B. Molinoff $(1979 \mathrm{c}) \beta_{1}$ and $\beta_{2}$-adrenergic receptors in rat cerebral cortex are independently regulated. Science 204: 866868.

Pfeiffer, S. E., B. Betschart, J. Cook, P. Mancini, and R. Morris (1977) Glial cell lines. In Cell Tissue and Organ Culture in Neurobiology, S. Federoff and L. Hertz, eds., pp. 287-346, Academic Press, New York.

SAS Institute, Inc. (1979) SAS Users Guide, pp. 316-329, SAS Institute, Inc., Cary, NC.

Scatchard, G. (1949) The attractions of proteins for small molecules and ions. Ann. N. Y. Acad. Sci. 51: 660-672.

Schachner, M., G. Schoonmaker, and R. O. Hynes (1978) Cellular and subcellular localization of LETS protein in the nervous system. Brain Res. 158: 149-158.

Stieg, P. E., H. K. Kimelberg, J. E. Mazurkiewicz, and G. A. Banker (1980) Distribution of glial fibrillary acidic protein and fibronectin in primary astroglial cultures from rat brain. Brain Res. 199: 493-500.

van Calker, D., M. Muller, and B. Hamprecht (1978) Adrenergic $\alpha$-and $\beta$-receptors expressed by the same cell type in primary culture of perinatal mouse brain. J. Neurochem. 30: 713-718.

Witkin, K. M., and T. K. Harden (1981) A sensitive equilibrium binding assay for soluble $\beta$-adrenergic receptors. J. Cyclic Nucleotide Res. 7: 235-246. 